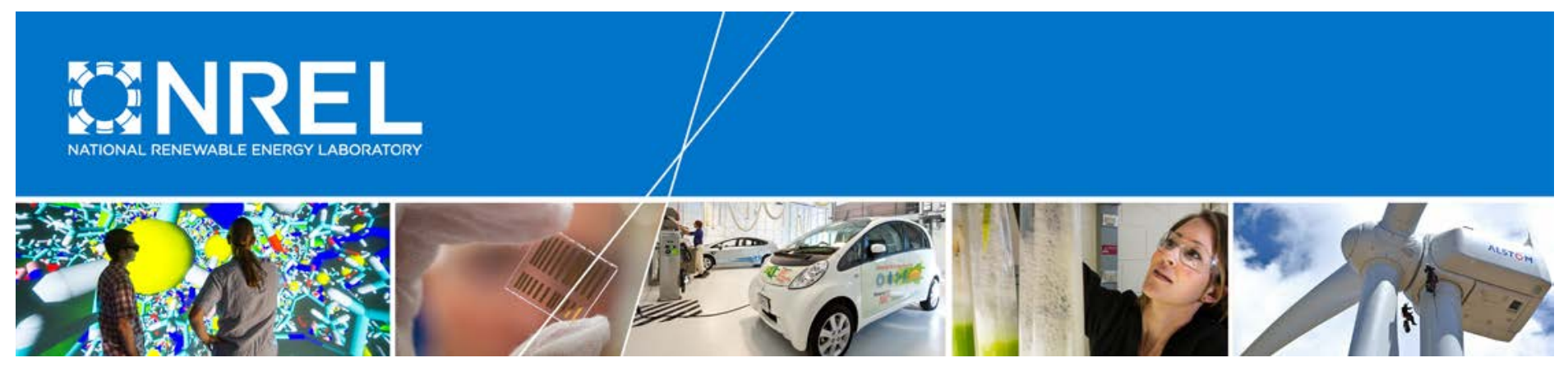

\title{
An Analysis of Home Energy Score and REM/Rate Energy Simulation Results for Homes in Three Climates
}

Noel Merket

National Renewable Energy Laboratory

NREL is a national laboratory of the U.S. Department of Energy Office of Energy Efficiency \& Renewable Energy Operated by the Alliance for Sustainable Energy, LLC

This report is available at no cost from the National Renewable Energy Laboratory (NREL) at www.nrel.gov/publications.

Technical Report

NREL/TP-5500-71072

June 2018 


\title{
An Analysis of Home Energy Score and REM/Rate Energy Simulation Results for Homes in Three Climates
}

\author{
Noel Merket
}

National Renewable Energy Laboratory

\section{Suggested Citation}

Merket, Noel. 2018. An Analysis of Home Energy Score and REM/Rate Energy Simulation Results for Homes in Three Climates. Golden, CO: National Renewable Energy Laboratory. NREL/TP-5500-71072.

https://www.nrel.gov/docs/fy18osti/71072.pdf

NREL is a national laboratory of the U.S. Department of Energy Office of Energy Efficiency \& Renewable Energy Operated by the Alliance for Sustainable Energy, LLC

This report is available at no cost from the National Renewable Energy Laboratory (NREL) at www.nrel.gov/publications.

National Renewable Energy Laboratory 15013 Denver West Parkway Golden, CO 80401

303-275-3000 • www.nrel.gov

\section{Technical Report}

NREL/TP-5500-71072

June 2018

Contract No. DE-AC36-08GO28308 


\section{NOTICE}

This report was prepared as an account of work sponsored by an agency of the United States government. Neither the United States government nor any agency thereof, nor any of their employees, makes any warranty, express or implied, or assumes any legal liability or responsibility for the accuracy, completeness, or usefulness of any information, apparatus, product, or process disclosed, or represents that its use would not infringe privately owned rights. Reference herein to any specific commercial product, process, or service by trade name, trademark, manufacturer, or otherwise does not necessarily constitute or imply its endorsement, recommendation, or favoring by the United States government or any agency thereof. The views and opinions of authors expressed herein do not necessarily state or reflect those of the United States government or any agency thereof.

This report is available at no cost from the National Renewable Energy Laboratory (NREL) at www.nrel.gov/publications.

Available electronically at SciTech Connect http:/www.osti.gov/scitech

Available for a processing fee to U.S. Department of Energy and its contractors, in paper, from:

U.S. Department of Energy

Office of Scientific and Technical Information

P.O. Box 62

Oak Ridge, TN 37831-0062

OSTI http://www.osti.gov

Phone: 865.576.8401

Fax: 865.576.5728

Email: reports@osti.gov

Available for sale to the public, in paper, from:

U.S. Department of Commerce

National Technical Information Service

5301 Shawnee Road

Alexandria, VA 22312

NTIS http://www.ntis.gov

Phone: 800.553 .6847 or 703.605 .6000

Fax: 703.605.6900

Email: orders@ntis.gov 


\section{List of Acronyms}

$\begin{array}{ll}\text { DOE } & \text { U.S. Department of Energy } \\ \text { HERS } & \text { Home Energy Rating System } \\ \text { HEScore } & \text { Home Energy Score } \\ \text { HPXML } & \text { Home Performance XML } \\ \text { RESNET } & \text { Residential Energy Services Network }\end{array}$




\section{Abstract}

Energy ratings and scores for homes attempt to give homeowners a metric to compare the energy efficiency of homes. Two rating systems in the marketplace are the Residential Energy Services Network's (RESNET's) Home Energy Rating System (HERS) and the U.S. Department of Energy's (DOE's) Home Energy Score (HEScore). Each system utilizes differing energy calculation methodologies. This report compares the energy predictions from both REM/Rate ${ }^{\mathrm{TM}}$, a commonly used HERS rating tool, and HEScore for populations of real homes in three climates and determines some features of homes that lead to the greatest differences between energy predictions. 


\section{Table of Contents}

1 Introduction $\quad 1$

2 Methodology 3

2.1 Simulation and Translation Workflow $\ldots \ldots \ldots \ldots \ldots \ldots$

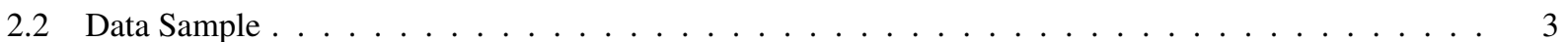

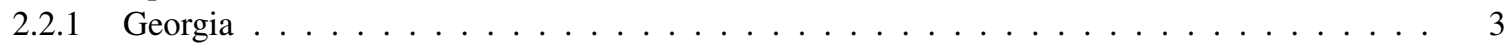

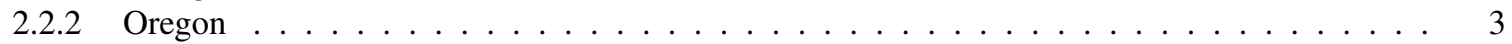

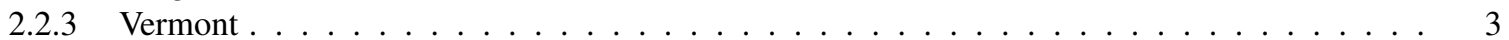

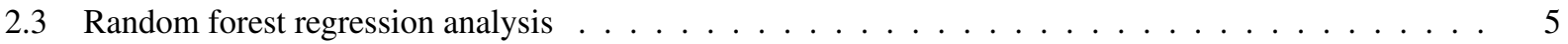

3 Results and Discussion 6

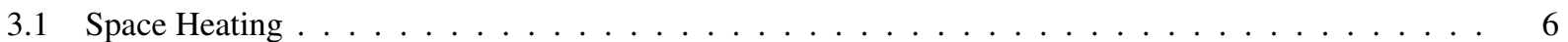

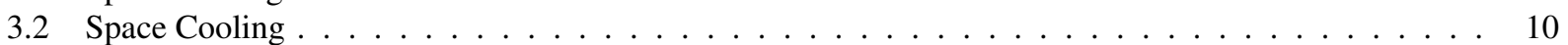

3.3 Domestic Hot Water . . . . . . . . . . . . . . . . . . . . . . . . 11

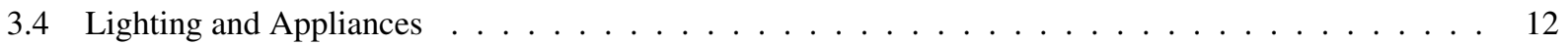

4 Conclusion $\quad 13$

5 Appendix A: REM/Rate to Home Energy Score Translation Engineering Assumptions 15

$5.1 \quad \mathrm{REM} /$ Rate to HPXML $\ldots \ldots \ldots \ldots \ldots \ldots \ldots \ldots$

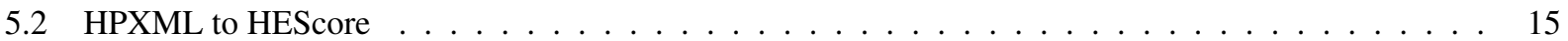

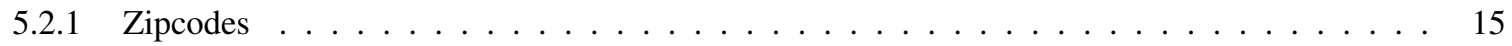

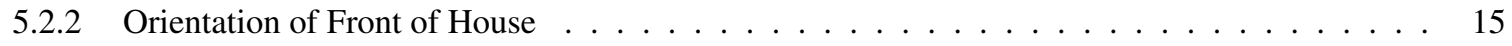

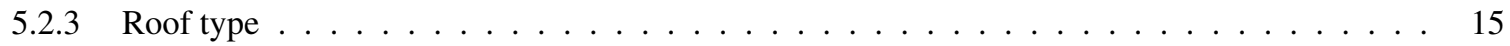

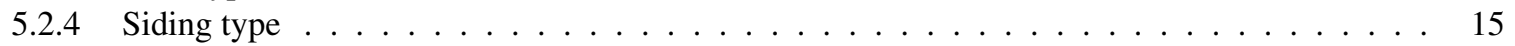

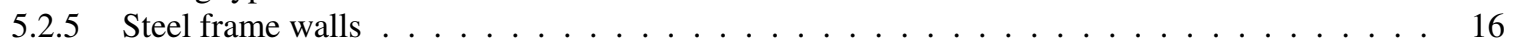

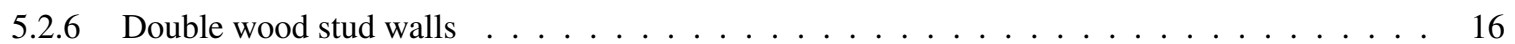

5.2 .7 Heat pumps . . . . . . . . . . . . . . . . . . . . . . . . . . . 16

5.2 .8 Wall furnaces . . . . . . . . . . . . . . . . . . . . . . . . . . . . 16

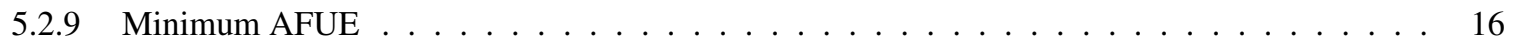

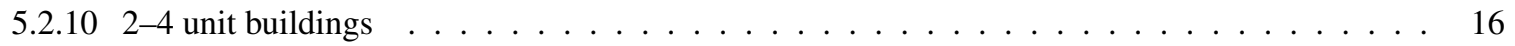

5.2 .11 Maximum ceiling height $\ldots \ldots \ldots \ldots \ldots \ldots \ldots \ldots$

5.2 .12 Photovoltaic year installed $\ldots \ldots \ldots \ldots \ldots \ldots \ldots \ldots$

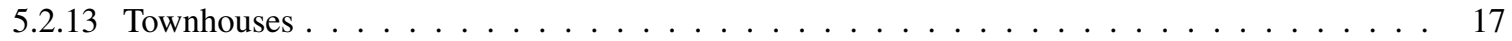




\section{List of Figures}

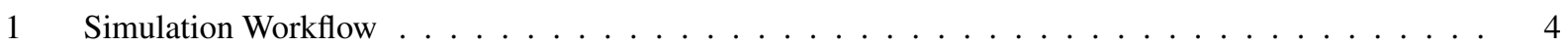

2 Site natural gas heating energy . . . . . . . . . . . . . . . . . . . 7

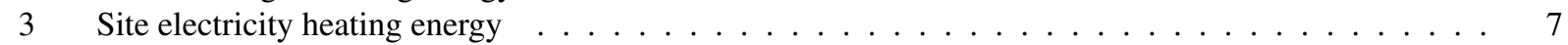

4 Site propane heating energy . . . . . . . . . . . . . . . . . . . 7

5 Natural gas heating difference in Oregon and Vermont by foundation type . . . . . . . . . . . . 8

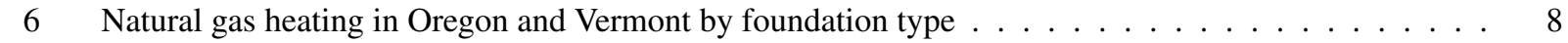

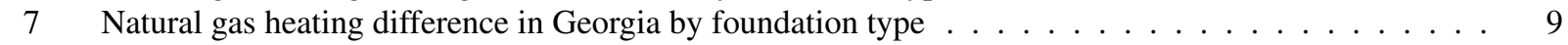

8 Natural gas heating in Georgia by foundation type . . . . . . . . . . . . . . . . . 9

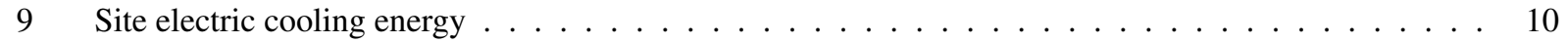

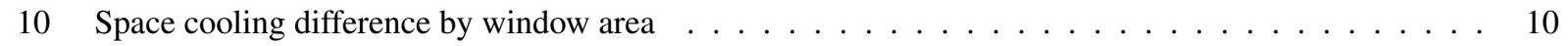

11 Natural gas water heating energy . . . . . . . . . . . . . . . . . . . . . . 11

12 Electric water heating energy . . . . . . . . . . . . . . . . . . . . . 11

13 Electric water heating energy use in Oregon and Vermont . . . . . . . . . . . . . . . . . . . . 12

14 Lights and appliances electric energy . . . . . . . . . . . . . . . . . . . . . . . 12 


\section{List of Tables}

1 Qualitative Comparison of RESNET HERS and Home Energy Score . . . . . . . . . . . . . . . . 2 


\section{Introduction}

Potential homeowners consider many data points when deciding what home to buy-from the neighborhood and schools to the color of the paint and the finish of appliances. One data point that is difficult to consider is the ongoing energy costs. To give customers a "miles-per-gallon" rating for a home, several home energy rating or scoring systems have been developed where an assessor measures several features of the house, inputs them into a computer program that predicts energy usage, and creates a score or rating for the home that can be compared to other homes. However, the scoring or rating methodology is not consistent across programs and platforms and can lead to ongoing confusion in the marketplace.

In this paper, we consider the methodologies of two rating and scoring systems and how those methodologies affect the energy predictions used to inform homeowners:

- The Residential Energy Service Network (RESNET) Home Energy Rating System (HERS) as implemented in the REM/Rate ${ }^{\mathrm{TM}}$ computer software

- DOE Home Energy Score (HEScore)

Each of these scoring systems takes a different approach to determine the consumer-facing score or rating. Both approaches are summarized in Table 1. The workflows are similar in that both take details of the building, which are then used in computer programs to predict the annual energy use of the building broken out by end use (space heating, space cooling, hot water, lights, appliances, and miscellaneous loads). Finally the energy use prediction is used to determine a score according to the particular methodology of that scoring or rating system.

Comparing the score or rating metric directly is not particularly informative because each system rewards different features of a home. For example, HERS attempts to normalize the size of the house in the rating by comparing to a IECC 2006 code-built house that is the same size whereas HEScore penalizes larger houses for using more absolute energy than an average sized home. Which approach is preferred is a function of policy and up for discussion.

One promising alternative is to determine a common metric between the rating and scoring systems such as source energy use, carbon emissions, or total utility bill cost. To establish such a metric, an important step is to understand and align the energy predictions between the models. The energy predictions can and do vary depending on the modeling engine used and the assumptions and defaults that drive the model. Within the HERS rating ecosystem, there are multiple energy modeling software programs available. While they use the same rule set (ANSI/RESNET 2014) for defaults and assumptions, the energy predictions vary and are a subject for study and discussion that is outside the scope of this report. The goal of this report is to compare the inputs and outputs of the energy use prediction for both REM/Rate - a commonly used software to calculate HERS ratings - and HEScore to discern which assumptions and energy modeling techniques are driving the differences. Knowing what models drive the difference in energy prediction identifies what areas to target in aligning that prediction to calculate a common metric. 
Table 1. Qualitative Comparison of RESNET HERS and Home Energy Score

\begin{tabular}{|l||l|l|}
\hline Primary Market & RESNET HERS & Home Energy Score \\
\hline Audit Detail & New homes & Existing homes \\
\hline $\begin{array}{l}\text { Energy Modelling } \\
\text { Assumptions }\end{array}$ & $\begin{array}{l}\text { ANSI-RESNET 301 (ANSI/RES- } \\
\text { NET 2014) }\end{array}$ & $\begin{array}{l}\text { Lower level of audit detail } \\
\text { Bouse } \text { Himulation Protocols } \\
\text { (Hendron and Engebrecht 2010) }\end{array}$ \\
\hline $\begin{array}{l}\text { Energy Simulation } \\
\text { Engine }\end{array}$ & $\begin{array}{l}\text { Various; we will consider } \\
\text { REM/Rate in this report }\end{array}$ & DOE2.1e \\
\hline Scoring Approach & $\begin{array}{l}\text { Energy use of as-rated house is } \\
\text { compared to the energy use of } \\
\text { a similarly-sized house built to } \\
\text { IECC 2006 energy code }\end{array}$ & $\begin{array}{l}\text { Energy use of as-assessed house } \\
\text { is compared to a nationwide } \\
\text { distribution of residential energy } \\
\text { use normalized for local weather }\end{array}$ \\
\hline $\begin{array}{l}\text { 0-100. Lower scores are better, } \\
\text { with a score of 100 being gen- } \\
\text { erally equivalent to a code-built } \\
\text { new home with the same size, and } \\
\text { a score of zero being a net-zero } \\
\text { energy home. A home that is a net } \\
\text { producer of energy could achieve } \\
\text { a score less than zero. Likewise, } \\
\text { a home that is less efficient than a } \\
\text { code-built home will score above } \\
\text { 100. }\end{array}$ & $\begin{array}{l}\text { 1-10. Higher scores are better, } \\
\text { with a 10 representing a home that } \\
\text { is in the 10th percentile of energy } \\
\text { use (i.e., uses less energy than } \\
\text { 90\% of homes), a 1 representing } \\
\text { a home in the 85th percentile, } \\
\text { and a 5 being a median energy- } \\
\text { using home. Percentiles of energy } \\
\text { use are relative to the 2009 EIA } \\
\text { Residential Energy Consumption } \\
\text { Survey microdata (EIA 2009). }\end{array}$ \\
\hline
\end{tabular}




\section{Methodology}

\subsection{Simulation and Translation Workflow}

To compare the energy use predictions of both the REM/Rate and HEScore models, it was necessary to simulate the same buildings through both REM/Rate and Home Energy Score. Several data samples from around the country in REM/Rate building format were collected and used for this purpose. Details about the data samples are in Section 2.2. Personally identifiable information was removed. The homes were simulated through REM/Rate v15.3 in batch mode and exported to a Microsoft Access database.

Each home's characteristics were parsed from the database and converted into Home Performance XML (HPXML)— a data transfer standard for home energy audits. The data as exported from REM/Rate were not entirely sufficient to describe a building for HEScore, so some engineering assumptions were applied as documented in Section 5 before translating the HPXML file into Home Energy Score inputs using the official HPXML translator for Home Energy Score (Merket 2018).

Each building was then simulated through the HEScore API and the results retrieved. All results and inputs were aggregated and stored in a Mongo database for further analysis. Figure 1 shows a diagram of the data flows and translation steps.

\subsection{Data Sample}

The home audit data for this analysis came from three locations, which represent a limited variety of climates. Each data set is described in more detail in the following sections. Generally, all the homes are new construction, which skews the analysis toward homes that perform better. The specific challenges of modeling older, poorly insulated, leaky homes will therefore not be captured here.

\subsubsection{Georgia}

The Georgia REM/Rate buildings files consisted of 941 new construction homes. These homes were a combination of EarthCents and IECC 2009 code homes, as well as a handful of ENERGY STAR Homes. EarthCents is primarily a Light and Appliance upgrade program and requires a maximum HERS Index of 76.

\subsubsection{Oregon}

The Oregon REM/Rate building files consisted assessments completed during 2016 and 2017 of 700 above code new construction homes provided by Energy Trust of Oregon and 300 existing homes provided by Earth Advantage. The total annual energy use of the new construction homes was modeled to be between $10 \%$ and $45 \%$ lower than the 2014 Oregon state code, which was equivalent to IECC 2015. The Oregon sample is a representative mix of electric and gas heating in new construction, different Oregon climate zones, and a mix of home sizes.

\subsubsection{Vermont}

The Vermont REM/Rate building files consisted of 1,066 above code new construction homes completed between 2014 and 2017. Homes rated after March 2015 were constructed while the 2015 Vermont Residential Building Energy Standard (2015 RBES) was in effect. Homes rated prior to this date were constructed while 2011 RBES was in effect. The sample included Efficiency Vermont's Certified and High Performance Home tiers. The data sample also included some High Performance Modular Homes that were sometimes characterized as single family detached homes in REM/Rate. Additionally, there were a small number of apartments units in the sample. The apartments were excluded from the analysis because HEScore cannot model apartments. The apartment units and modular 


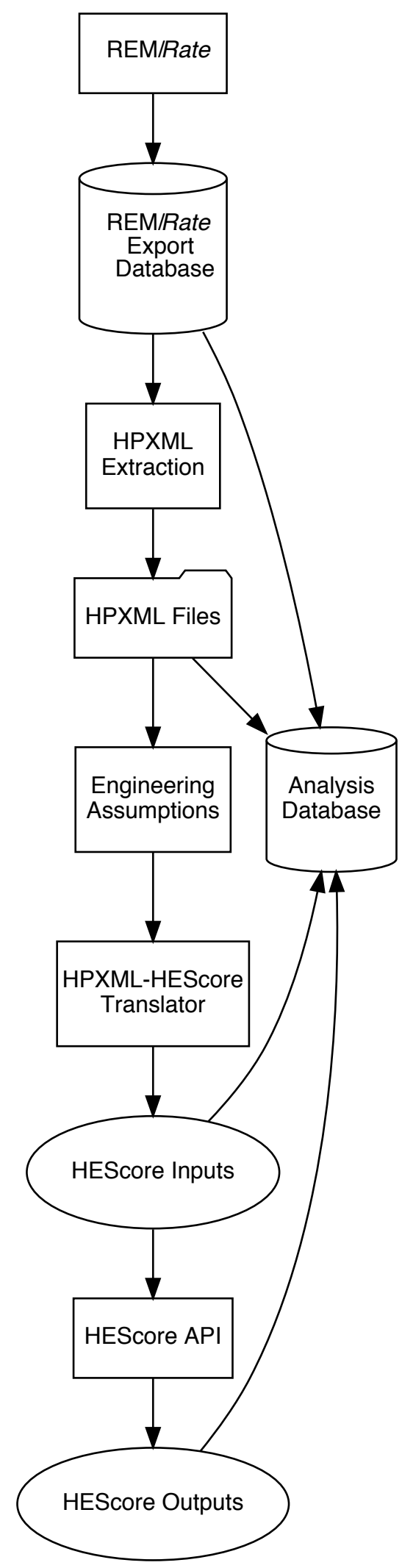

Figure 1. Simulation Workflow 
homes comprise less than $5 \%$ of the sample and should not impact the analysis. The homes will likely appear as outliers.

\subsection{Random forest regression analysis}

The random forest machine learning technique was used to build a regression model of the difference in predicted energy use by fuel type. Data input to the random forest model were preconditioned from the HEScore inputs to make more logical regression parameters. HEScore allows multiple wall, window, floor, and roof areas each with their own R-values. Rather than putting each wall and area in separately as separate features, which could confuse the model, an average area-weighted R-value was calculated for all the walls as in Eq. 2.1. An area-weight R-value was similarly calculated for roofs, ceilings, floors, and foundation walls.

$$
R_{a v g}=\frac{1}{U_{a v g}}=\frac{\sum A_{i}}{\sum \frac{A_{i}}{R_{i}}}
$$

The foundation type, wall construction type, exterior finishes, etc., with the largest areas were used as well as the heating and cooling equipment and duct locations that serve the greatest portions of the load. Window properties included averages for the whole building and for the south facing windows.

This simplified input array of building characteristics was used to train the random forest regressor from Scikit Learn (Pedregosa et al. 2011) with 500 decision trees. The model was trained using $75 \%$ of the data. The remaining $25 \%$ were used to test the regression fit. The dependent variable was the percent difference as calculated by Eq. 2.2 between REM/Rate and HEScore predicted energy use for a particular end use.

$$
\Delta E \%=\frac{E_{R E M}-E_{\text {HEScore }}}{E_{\text {HEScore }}}
$$

Because more data provide a better fit for the regression, the Oregon and Vermont data samples were combined for this part of the analysis as they are both primarily heating climates. Homes with indirect water heaters were removed from the sample because HEScore and REM/Rate attribute the energy in the water heating system to different end uses.

The most useful outputs of the random forest in this case are the feature importance weights, which indicate building characteristic inputs to Home Energy Score that most consistently predict a difference with REM/Rate predictions. Percent difference was chosen because absolute energy difference caused floor area to always be the most important feature of the regression because it is the largest driver of overall energy use. 


\section{Results and Discussion}

\subsection{Space Heating}

For our data samples REM/Rate generally predicted higher space heating energy for both natural gas (Figure 2) and electricity (Figure 3) in all climates. Propane use was only available in Vermont, and the space heating energy for that fuel type didn't show any particular bias toward one modeling engine, but a high variance as shown in Figure 4. The natural gas energy use in Vermont (Figure 2) shows two very distinct groupings, with one group REM/Rate predicting higher energy use than HEScore and the other more closely agreeing.

To determine which features of the model predicted the differences in space heating energy prediction, a random forest regression model was applied to the HEScore inputs from the combined Oregon and Vermont data samples as independent variables and the percent difference in energy predictions as the dependent variable. For natural gas heating fuel use, the correlation coefficient for the test set was $r^{2}=0.511$, which indicates that not all the difference was attributable to specific features of the HEScore inputs. Potentially features of the home lost in translation from REM/Rate could be the drivers for the remaining difference. Nevertheless, the random forest proved useful for identifying inputs that should be investigated further.

The most important features of the regression were the foundation insulation level followed by the foundation type inputs to HEScore. The foundation insulation level input is only used for certain foundation types and is zero for crawlspaces where the the insulation level is recorded in a different feature. Therefore those two features are colinear and the primary driving factor in the difference is the foundation type.

As can be seen in the violin plot in Figure 5, for conditioned basements the mean difference in natural gas heating is $95 \%$, while the rest are all in the 20\%-30\% range. Looking at it another way in Figure 6, the cluster of homes with the largest differences are predominantly conditioned basements, which points to a potential difference in the way foundation heat transfer is calculated between the two modeling engines.

Performing a similar random forest regression on the Georgia data yielded a correlation coefficient $r^{2}=0.477$ and identified foundation type as the most important feature followed by envelope leakage and window area as weaker drivers. Plotting the percent difference grouped by foundation type in a violin plot in Figure 7 shows that the slab on grade foundation type was most correlated with heating energy prediction differences with a mean of $42 \%$ higher heating energy use in REM/Rate for that foundation type. Heating energy use for conditioned basements predicts roughly the same use between the modeling engines, which is notably different from the Oregon and Vermont data set. However, the sample size for conditioned basements in the Georgia data is relatively small, so it is not prudent to draw conclusions from it. In Figure 8 we see a consistent trend of higher heating energy prediction in REM/Rate for slab on grade foundations and a lesser but still higher energy prediction for unconditioned basements. Again, this suggests a fundamental modeling difference in ground coupling. Foundations such as conditioned basements and slab on grade, where a larger surface area interacts between conditioned space and the ground, show the largest differences; while foundations with a buffer space such as unconditioned basements that are not as tightly coupled show better agreement. 

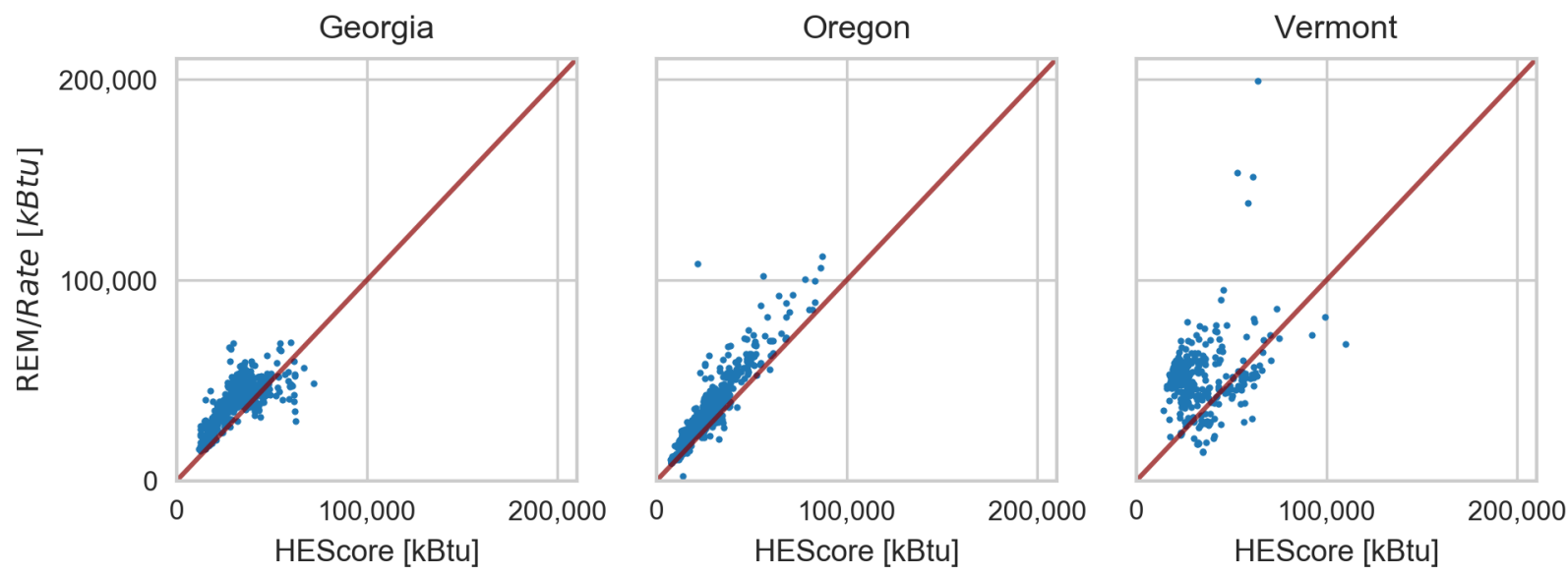

Figure 2. Site natural gas heating energy
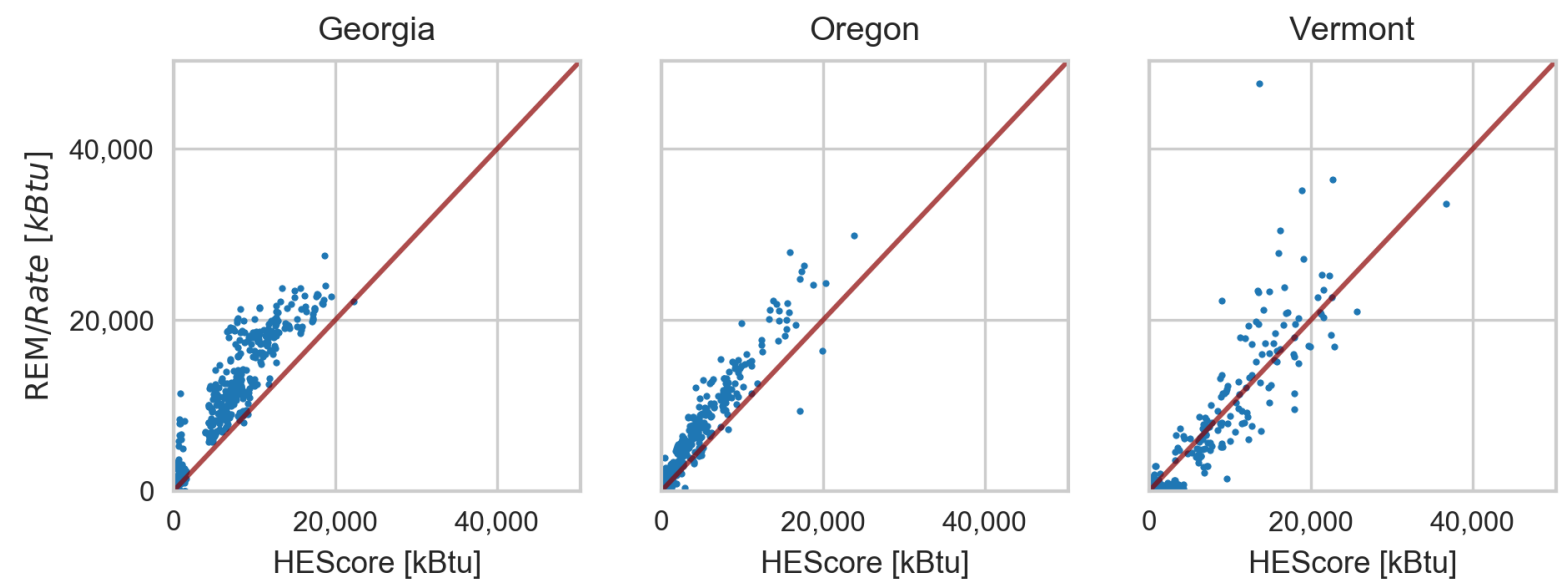

Figure 3. Site electricity heating energy
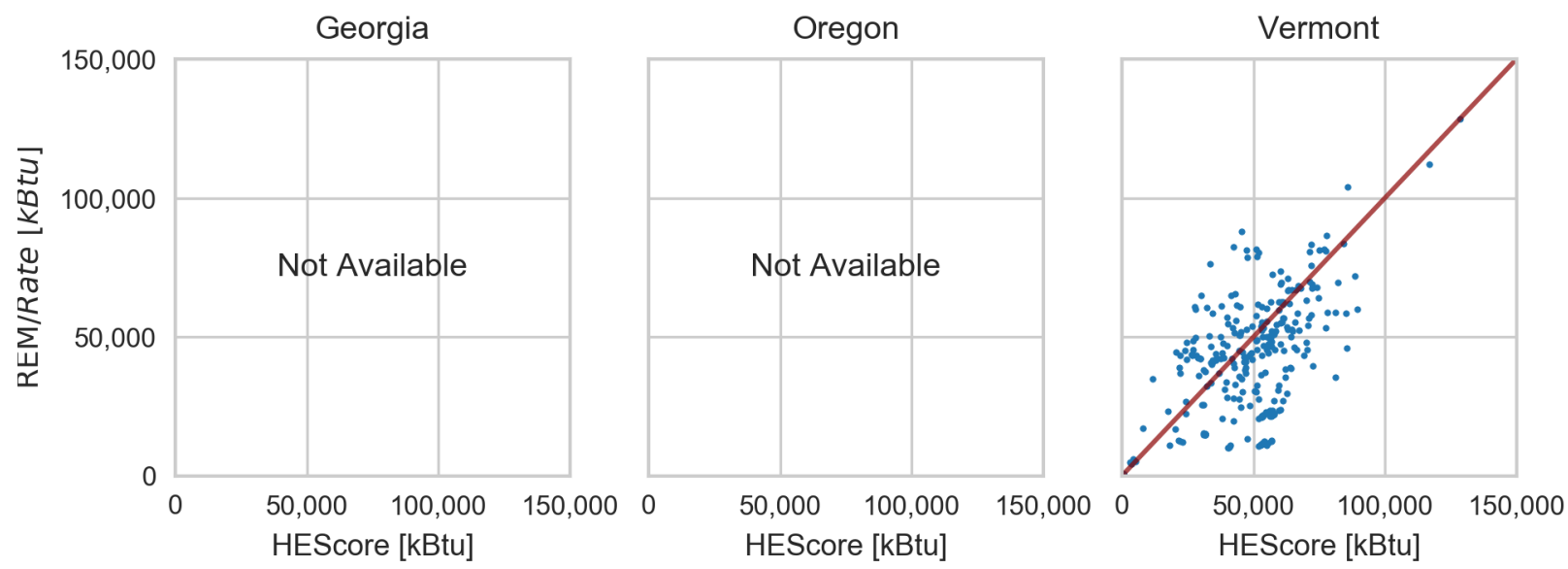

Figure 4. Site propane heating energy 


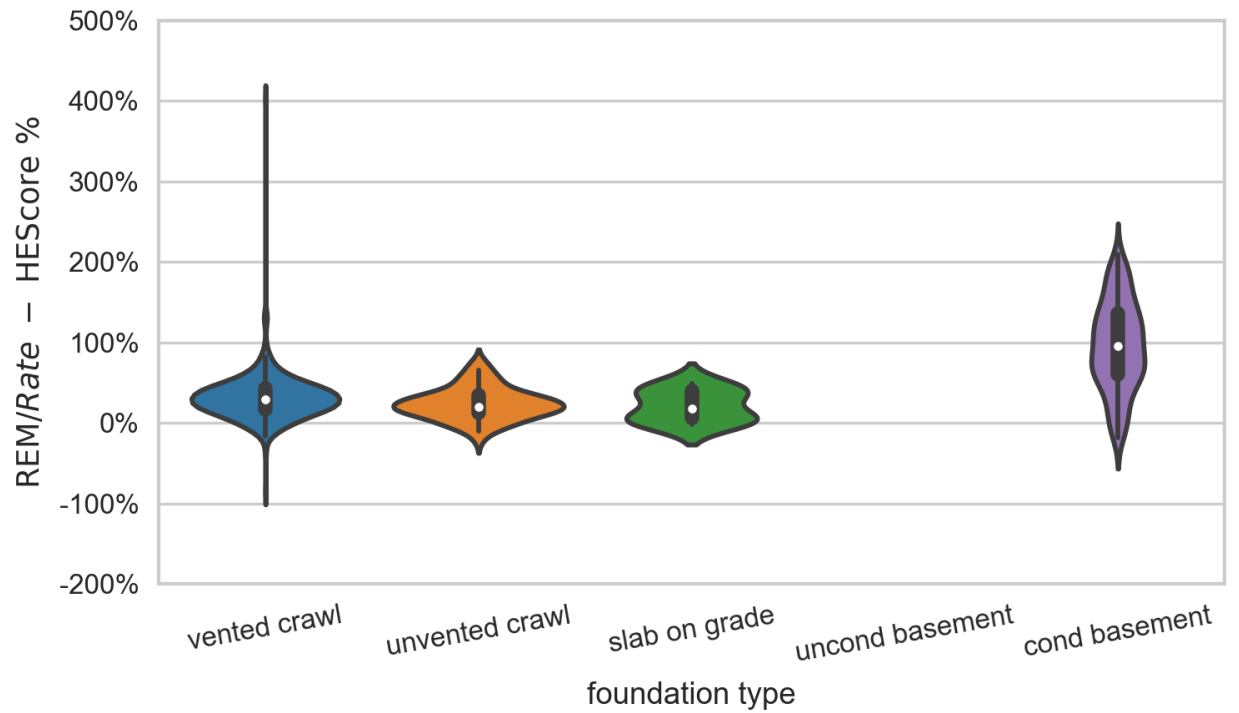

Figure 5. Natural gas heating difference in Oregon and Vermont by foundation type

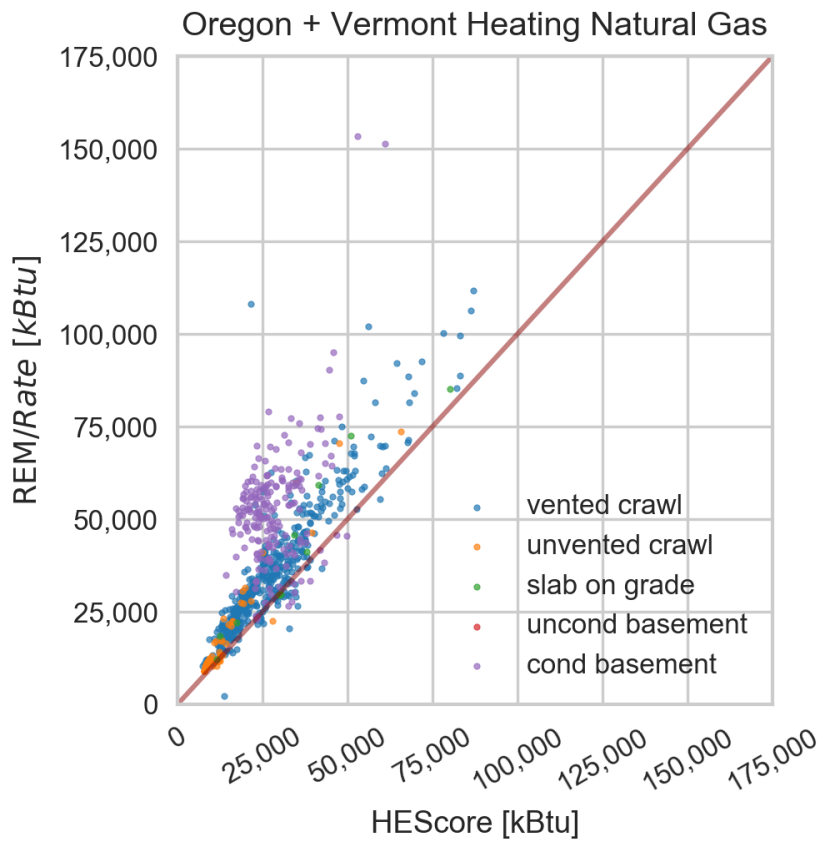

Figure 6. Natural gas heating in Oregon and Vermont by foundation type 


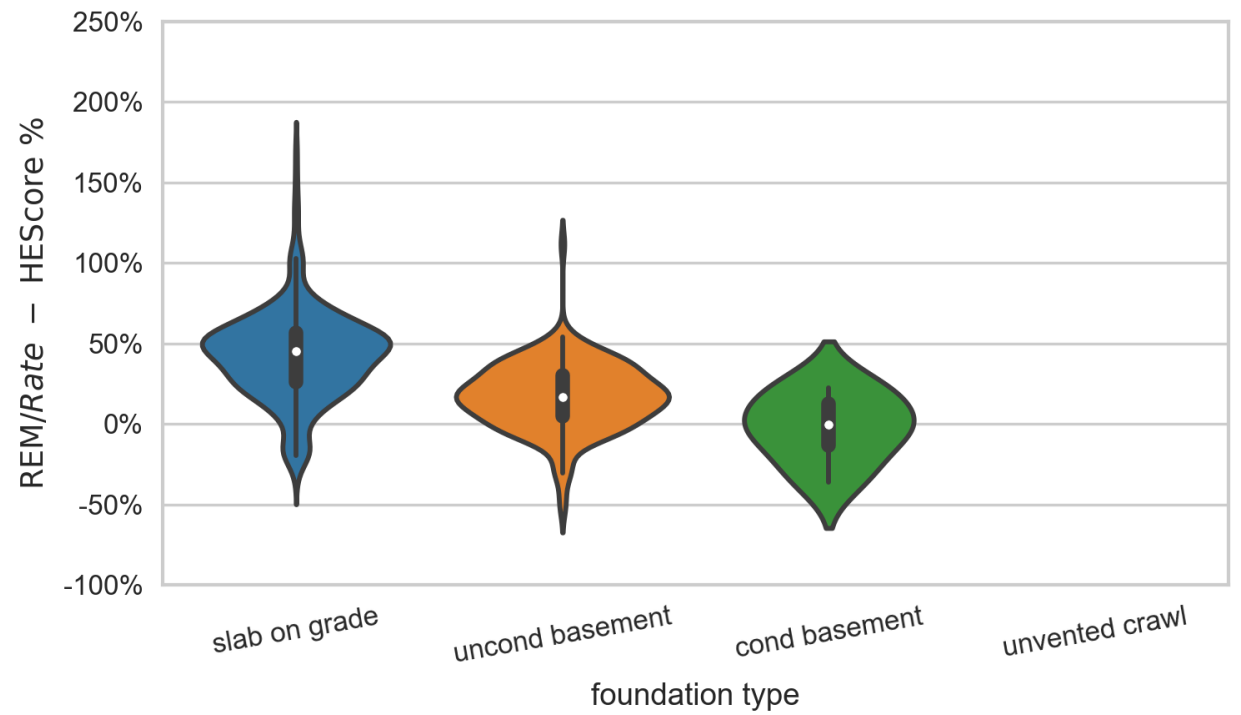

Figure 7. Natural gas heating difference in Georgia by foundation type

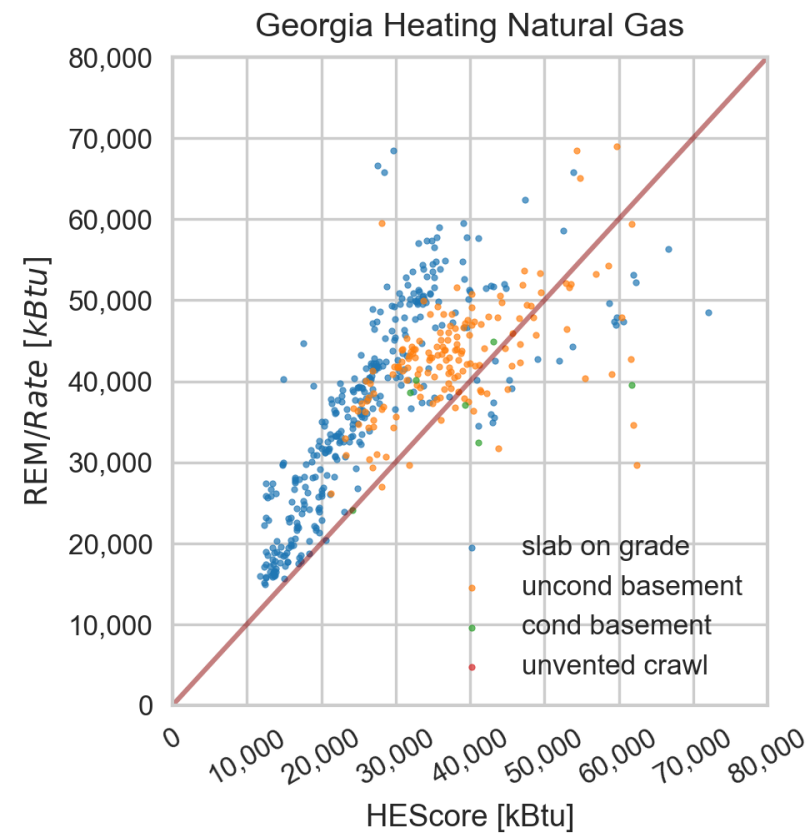

Figure 8. Natural gas heating in Georgia by foundation type 


\subsection{Space Cooling}

Figure 9 shows the space cooling electric energy use predictions comparing REM/Rate and HEScore for all three climates. In Oregon and Vermont where cooling loads are lower, there is generally good agreement between the two with REM/Rate predicting higher for some houses in Oregon.
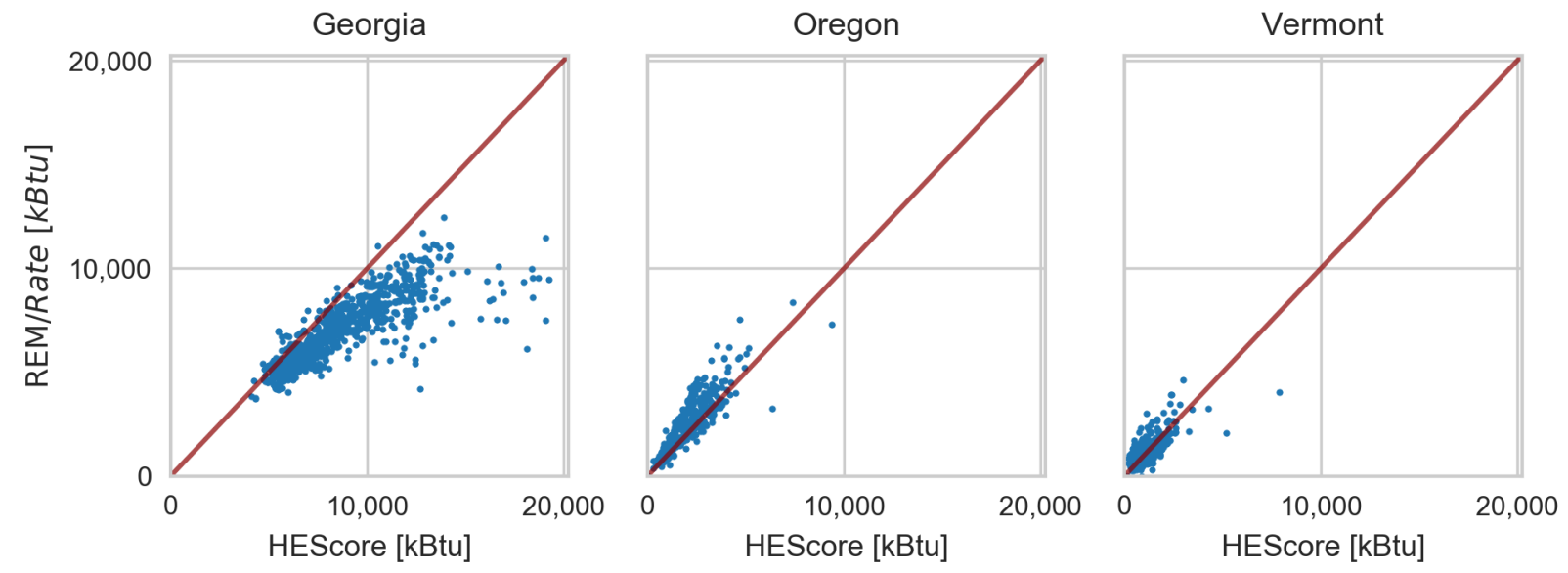

Figure 9. Site electric cooling energy

The random forest model fit with an $r^{2}$ of 0.500 and 0.511 for the Oregon/Vermont and Georgia data samples, respectively, indicates some correlation between building features and differences in prediction results, but not a strong correlation. One of the top predictors in both data samples was total window area. However, as seen in Figure 10, the correlation trends in different directions depending on the data set. There is a similar cluster of homes in both data samples where REM/Rate is predicting lower cooling energy. However, in the Oregon/Vermont data sample there is also a very spread out cluster of homes where the differences in cooling energy do not seem to be attributable to any feature in the analysis. The Georgia sample potentially indicates some differences in the solar gain calculations between the simulation engines, but overall the driving features are inconclusive.
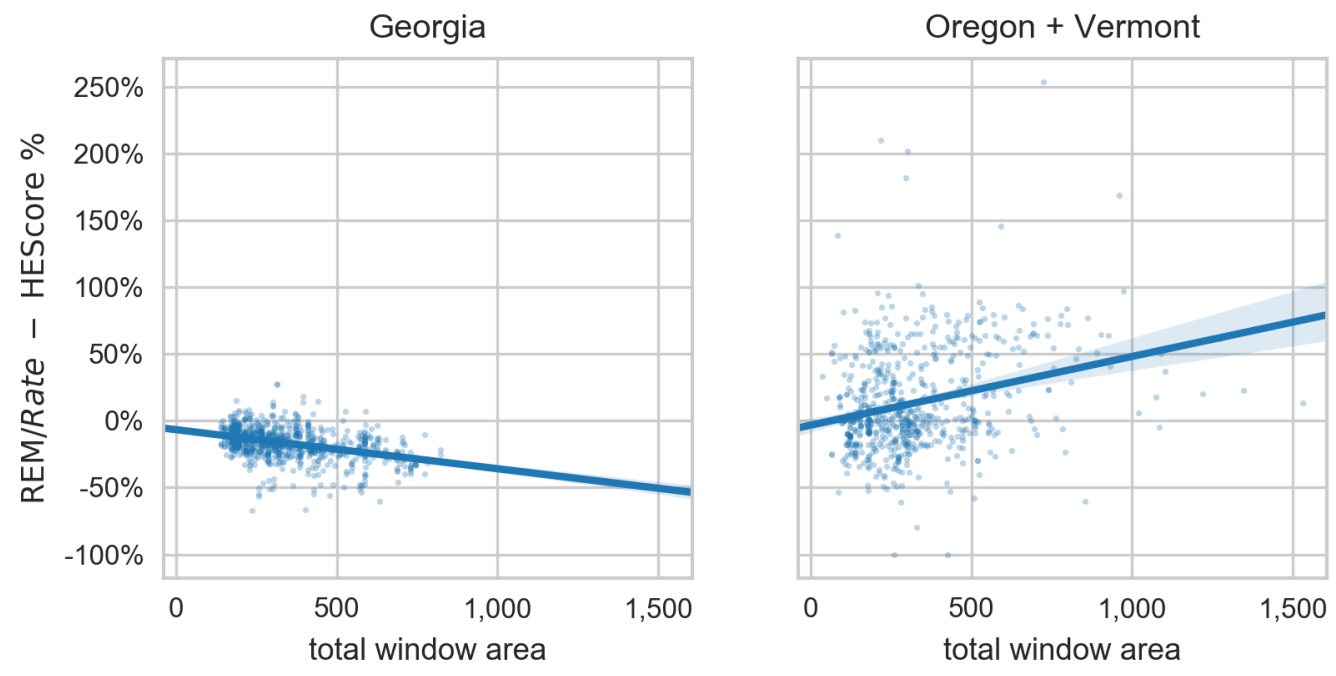

Figure 10. Space cooling difference by window area 


\subsection{Domestic Hot Water}

Figures 11 and 12 illustrate the differences in the water heating models between REM/Rate and HEScore. Natural gas water heater modeled energy use for all three data samples is quite closely correlated in Figure 11. Electric water heaters in Figure 12 were well correlated in Oregon and Georgia, but show REM/Rate predicting lower energy use than HEScore in Vermont.
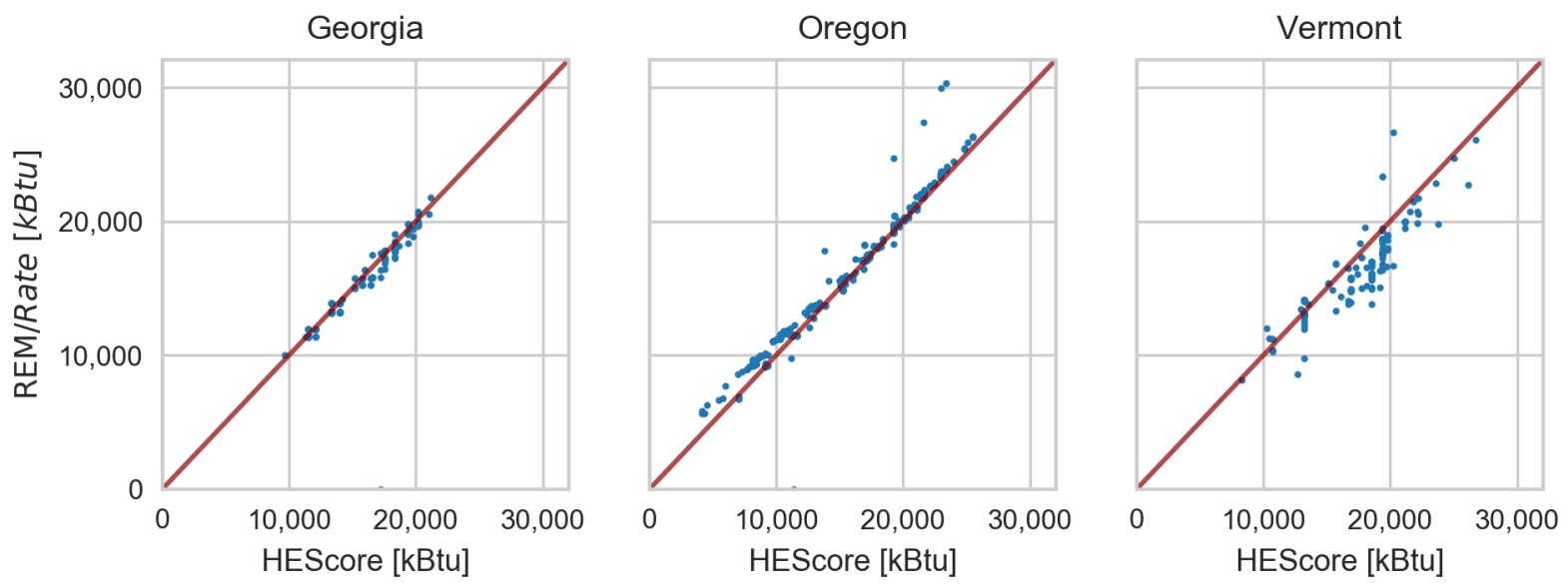

Figure 11. Natural gas water heating energy
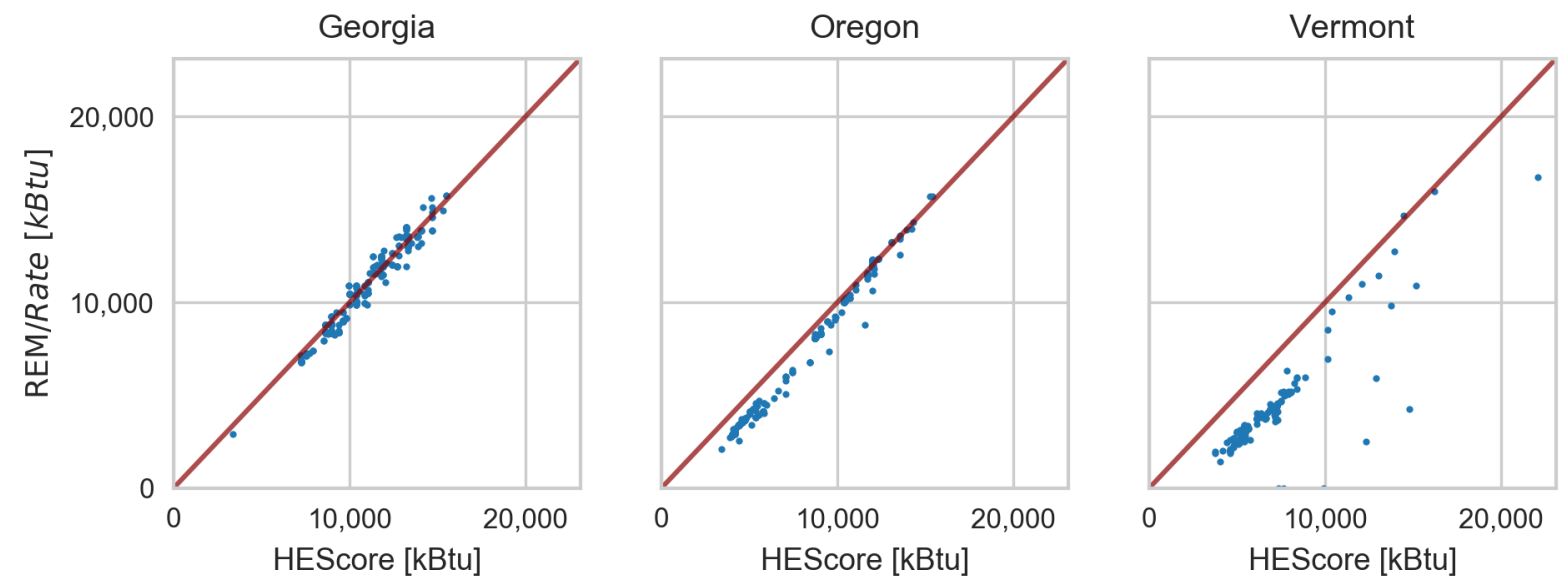

Figure 12. Electric water heating energy

Fitting a random forest to the percent difference between electric hot water energy use on the combined Oregon and Vermont data samples yielded a correlation coefficient of $r^{2}=0.881$. Such a high correlation coefficient indicates that most of the difference can be attributed to features of the model. The feature that most predicted the difference was water heater energy factor. Figure 13a shows that the cluster of water heaters with the greatest difference have an Energy Factor $>1$, which is only technically possible with heat pump water heaters. In Figure 13b, the same scatter plot is broken out by water heater type. The heat pump water heaters are clustered together with REM/Rate predicting lower electricity use than HEScore, which suggests a modeling difference between the two simulation engines for that class of water heaters. 
a.) Energy factor

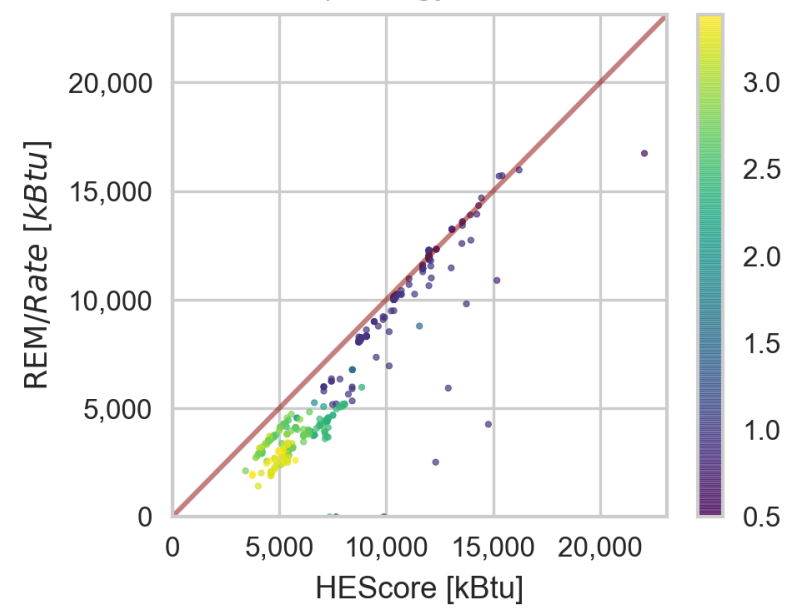

b.) Water heater type

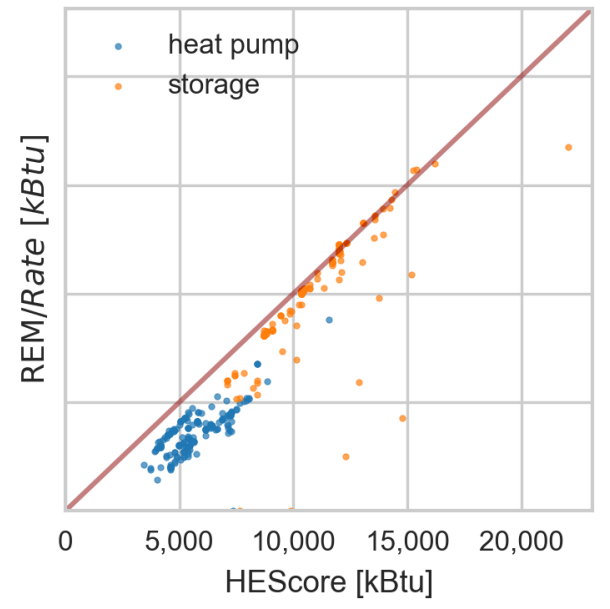

Figure 13. Electric water heating energy use in Oregon and Vermont

\subsection{Lighting and Appliances}

The lighting and appliance electric end use energy shows REM/Rate predicting less energy use in all three data samples (Georgia: 5\%, Oregon: 12\%, Vermont: 19\%) as seen in Figure 14. In HEScore, by design there are no user inputs for lighting and appliances and all loads are defaulted according to the Building America House Simulation Protocols (Hendron and Engebrecht 2010). Furthermore, this end use is omitted when calculating a score. In REM/Rate, some lighting and appliance inputs are available and others are defaulted according to the ANSI/RESNET 301 Ruleset (ANSI/RESNET 2014). Because no HEScore inputs are associated with lighting and appliances, a random forest regression was not performed on this end use. A better understanding of the differences and how to align them would be gained by comparing the modeling assumptions which was not attempted here.
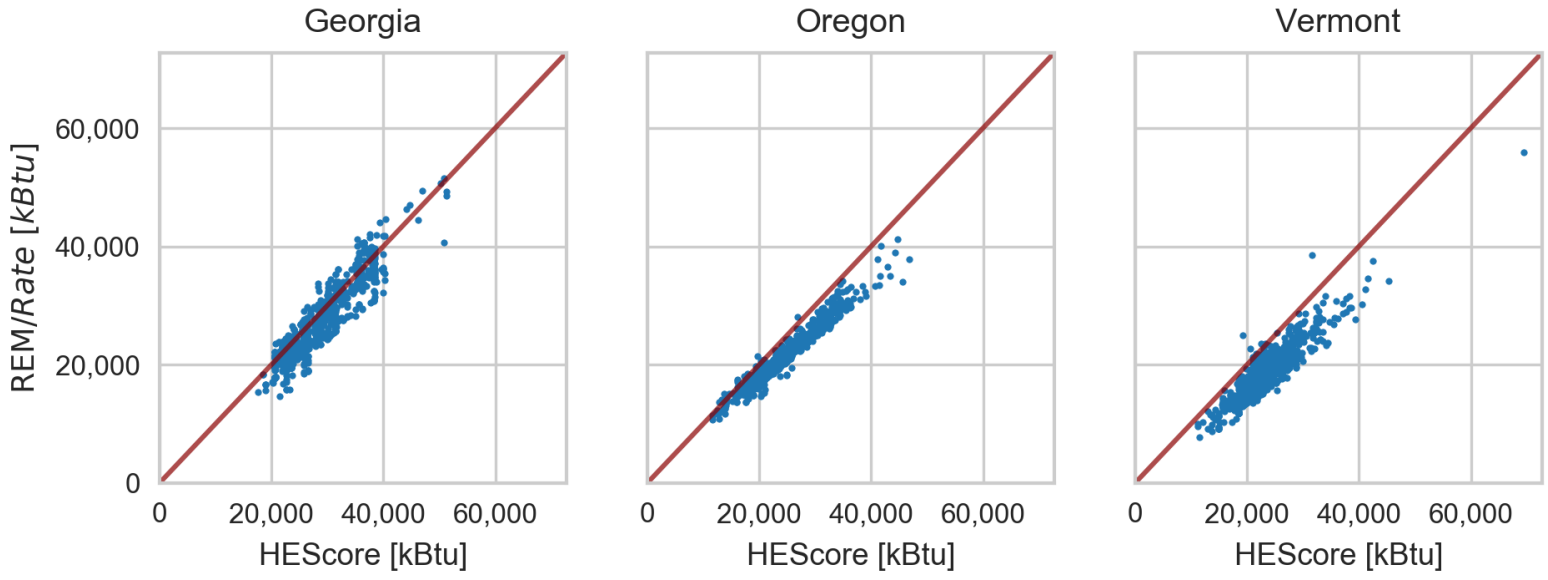

Figure 14. Lights and appliances electric energy 


\section{Conclusion}

Many factors play a role in driving differences between building energy simulation engines. There are differences in the engines themselves as well as differences in assumptions that need to be made between the high level inputs an auditor or assessor enters and the lower level simulation inputs. This report identifies a few areas of interest between the REM/Rate and HEScore where the modeling or assumptions differ. A few key findings include:

- Significantly higher predicted space heating energy in REM/Rate for homes with conditioned basements or, to a lesser extent, slab on grade. This points to a possible difference in modeling or assumptions about ground coupling.

- Space cooling energy use was lower in REM/Rate for larger homes with more window area, specifically in the Georgia data sample. While the results for this end use were inconclusive, differences in solar gain calculations could be a driver and may be worth further investigation.

- Heat pump water heaters had significantly lower predicted energy use in REM/Rate, indicating a difference in the way that technology is modeled.

- Lighting and appliance loads, which are mostly defaulted and assumed, had between 5\% and 19\% lower predicted electricity use in REM/Rate. Modeling of these technologies is fairly straightforward, so it implies a difference in the assumptions and defaults.

Further investigation into the assumptions and building energy simulation engines in these areas would be needed to identify specific differences in approaches. Ultimately, if the goal is to align energy predictions to provide a common metric between the HERS and HEScore consumer-facing ratings, both the differences in assumptions and modeling engines would need to be addressed and aligned. 


\section{Bibliography}

ANSI/RESNET. 2014. Standard for the Calculation and Labeling of the Energy Performance of Low-Rise Residential Buildings using the HERS Index. Standard. Oceanside, CA: American National Standards Institute.

EIA. 2009. Residential Energy Consumption Survey. Access March 21, 2018: https : / / www . eia . gov / consumption/residential/data/2009/.

Geonames. 2017. Postal Code Database. Access February 20, 2018: http: / / www - geonames . org/postalcodes/postal-codes-us.html.

Hendron, R., and C. Engebrecht. 2010. Building America House Simulation Protocols. Tech. rep. National Renewable Energy Laboratory. https: / / www.nrel.gov/docs/fy11osti/49246.pdf.

Merket, Noel. 2018. HPXML to Home Energy Score Documentation. Accessed February 20, 2018: http : / / hescore-hpxml.readthedocs.io/en/latest/.

Pedregosa, F., et al. 2011. "Scikit-learn: Machine Learning in Python". Journal of Machine Learning Research $12: 2825-2830$. 


\section{Appendix A: REM/Rate to Home Energy Score Translation Engi- neering Assumptions}

As described in Section 2, the translation from the REM/Rate v15.3 data model into Home Energy Score (HEScore) inputs happened in two primary steps:

1. REM/Rate to HPXML

2. HPXML to HEScore

The following sections describe assumptions made to enable simulation through both software tools.

\subsection{REM/Rate to HPXML}

The goal of this translation step is to export the REM/Rate audit data with little or no manipulation into equivalent HPXML files. It expects a REM/Rate database export from v15.3 and outputs a directory of HPXML v2.2 files. No assumptions were made in this step.

\subsection{HPXML to HEScore}

The primary translation from HPXML to HEScore is done with the official HPXML to HEScore translator. Assumptions and mapping for that translation are documented separately (Merket 2018).

However, the REM/Rate data exported into HPXML didn't have the information completely specified in the way HEScore requires without making some assumptions using engineering judgment. The following modifications were made to the HPXML file before sending it to the HEScore translator.

\subsubsection{Zipcodes}

For REM/Rate runs where a zipcode was provided, that zipcode was sent to HEScore which used it to determine the weather file to use. When a zipcode wasn't provided, a zipcode was looked up for the REM/Rate weather file city and state using Geonames (Geonames 2017).

\subsubsection{Orientation of Front of House}

HEScore requires the orientation of the front of the house. That is assumed by assuming the side of the house with the greatest window area is the back. Window areas are then attributed to sides of the house to give them their proper cardinal direction as specified in the REM/Rate input.

\subsubsection{Roof type}

Roofs are assumed to be standard composition shingles.

\subsubsection{Siding type}

Stucco is assumed for all siding. 


\subsubsection{Steel frame walls}

For homes with steel frame walls, the type was changed to wood stud wall. This is a poor assumption from a heat transfer perspective, but it is more in line with what an assessor would do.

\subsubsection{Double wood stud walls}

HEScore has no way to model double wood stud walls. To permit modeling in HEScore, those were changed to standard wood stud walls with "optimum value engineering" (i.e., studs farther apart, less thermal bridging) and a similar overall R-value construction was selected.

\subsubsection{Heat pumps}

Because HEScore requires the entire heat pump (heating and cooling) to serve a fraction of the load, when heating and cooling systems from REM/Rate support different portions of the load, the load fraction was averaged between heating and cooling.

REM/Rate instructs users to enter heat pumps as separate heating and cooling heat pump equipment objects. Those are combined into a single object for import into HEScore.

If a heat pump is specified in REM/Rate without a duct system, that heat pump type is changed to a mini-split before importing to HEScore.

\subsubsection{Wall furnaces}

Wall furnace efficiency is specified in REM/Rate as a percentage. HEScore expects an annual fuel utilization efficiency (AFUE). The units are changed to AFUE on import.

\subsubsection{Minimum AFUE}

REM/Rate allows users to specify a lower minimum AFUE than HEScore, which requires at least 60. If an AFUE lower than 60 is encountered, it is changed to 60 for HEScore.

\subsubsection{2-4 unit buildings}

Houses specified as 2-4 unit buildings are changed to town houses for import into HEScore.

\subsubsection{Maximum ceiling height}

In HEScore average ceiling height is a required input. That is estimated from the REM/Rate data by dividing the conditioned building volume by the floor area. At times this resulted in ceiling heights that were greater than $12 \mathrm{ft}$, which is the maximum allowed value in HEScore. In these cases, a ceiling height of $12 \mathrm{ft}$ was used.

\subsubsection{Photovoltaic year installed}

The year installed is a required input for HEScore photovoltaic systems, but it is not available in REM/Rate. 2015 was assumed in all cases. 


\subsubsection{Townhouses}

Townhouse orientation is a special case that requires some extra consideration. HEScore allows a townhouse to have attached walls on the right, left, or right and left sides. No other configurations are available. It does not permit windows to face the direction of an attached wall.

To determine which sides are attached, we look for orientations that do not have a window assigned to them. Those are assumed to be the attached walls. The front of the house orientation is adjusted accordingly to match one of the available HEScore configurations.

In cases where a house is marked as a townhouse, but has windows on all four sides, the windows are removed from the side with the least window area and that side is assumed to be the attached wall. 